\title{
Biliary obstruction caused by an erupted hepatic hydatid cyst
}

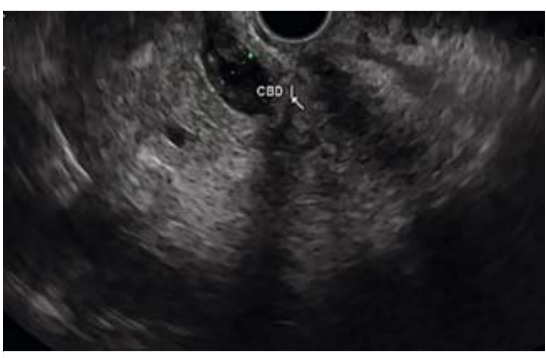

- Fig. 1 Endoscopic ultrasound shows a non-dilated common bile duct (CBD) containing a heterogeneous substance.

A 60-year-old woman presented to the emergency room with nausea and upper abdominal pain radiating to the back. Her past medical history was significant for an inactive hepatic hydatid cyst for 30 years. She had presented 4 months earlier with acute pancreatitis. Despite a negative abdominal ultrasound, a laparoscopic cholecystectomy was performed for presumed biliary pancreatitis.

On physical examination, a non-icteric, afebrile patient was seen. No tenderness or pain was observed during abdominal examination. Laboratory results showed elevated liver tests and a normal eosinophil count (AST 557U/l; ALT 535U/I; LD $754 \mathrm{U} / \mathrm{l}$; gamma-GT $440 \mathrm{U} / \mathrm{l}$; bilirubin 74 $\mu \mathrm{mol} / \mathrm{l}$ (conjugated $30 \mu \mathrm{mol} / \mathrm{l}$ ); eosinophils $\left.0.04 \times 10^{\wedge} 9 / \mathrm{I}\right)$. Endoscopic ultrasound showed a non-dilated common bile duct containing a heterogeneous substance (\$Fig.1). An endoscopic retrograde cholangiopancreatography (ERCP) was performed showing a protruding papilla ( $>$ Fig. 2 a). Immediately after cannulation, black fluid drained out of the papilla. Cholangiography suggested remaining material within the choledochal duct ( $\mathbf{F i g} \cdot \mathbf{3})$. After papillotomy, pus and a gelatinous substance of approximately 2 centimeters were

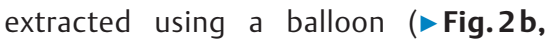
- Video 1). The material was aspirated and the pathology report noted its origin from a hydatid cyst. An abdominal computed tomography (CT) scan showed a

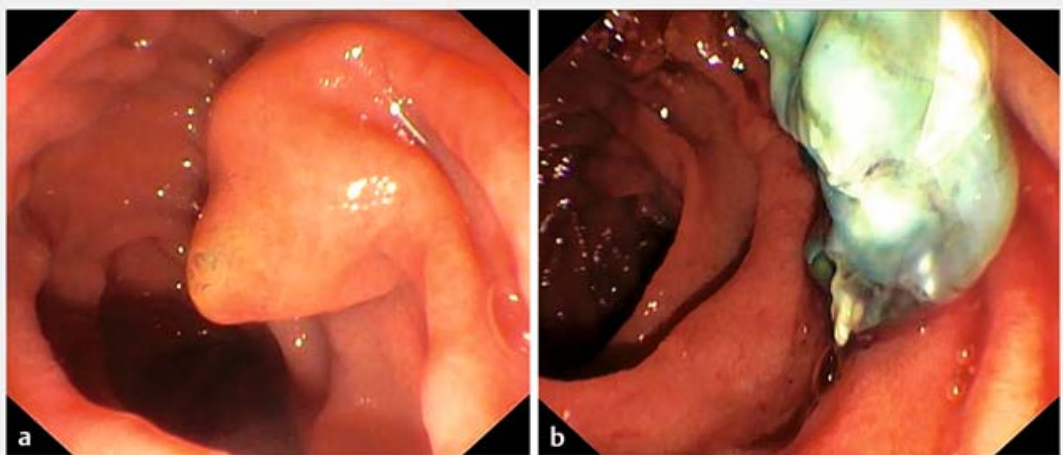

- Fig. 2 a Endoscopic retrograde cholangiopancreatography shows protruding papilla. b After papillotomy, a soft substance was extracted from the common bile duct.

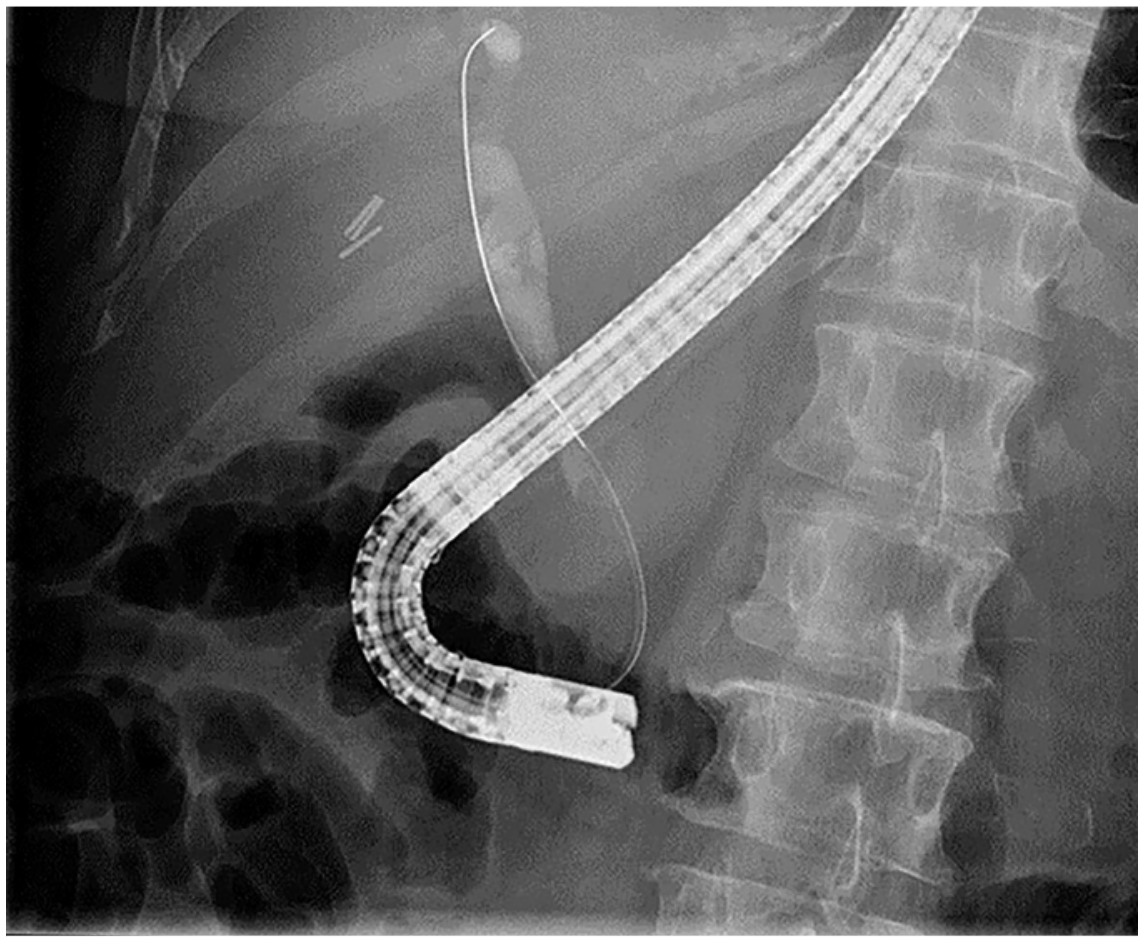

- Fig. 3 Cholangiography shows remaining material within the choledochal duct.

multilocular hydatid cyst of 66 by 48 millimeters, consistent with prior imaging ( Fig.4). Anthelmintic albendazole therapy was started and the patient was referred for percutaneous evacuation of cyst content [1].
Hepatic hydatid cysts are caused by parasitic infection through ingestion of eggs from the echinococcus tapeworm (Echinococcus granulosus) [2]. Biliary obstruction secondary to a frank intrabiliary rupture occurs in up to $17 \%$ of cases $[3,4]$. The prior episode of acute pancreatitis in 


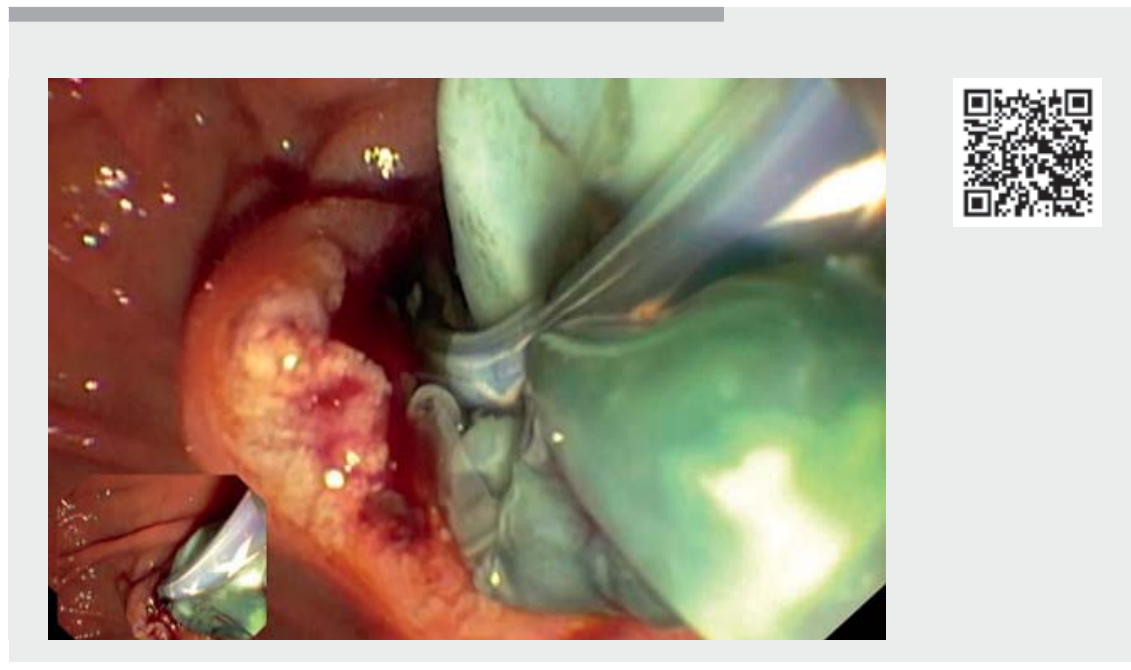

Video 1 Endoscopic extraction of hepatic hydatid cyst material. During cannulation black fluid drained out of the papilla. After papillotomy, a soft substance of approximately two centimeters was extracted using a balloon.

our patient might have been caused by an earlier eruption [5]. Primary treatment of intrabiliary rupture consists of balloon extraction by ERCP followed by percutaneous or surgical treatment and albendazole therapy for 1 to 3 months [1-4].

Endoscopy_UCTN_Code_TTT_1AR_2AK

\section{Competing interests}

The authors declare that they have no conflict of interest.

The authors

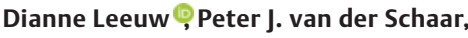
Roeland Zoutendijk

St. Antonius Hospital, Department of

Gastroenterology, Nieuwegein, The Netherlands

\section{Corresponding author}

\section{Dianne Leeuw}

St. Antonius Hospital, Department of Gastroenterology, Koekoekslaan 1, 3435 CM Nieuwegein, The Netherlands d.leeuw@antoniusziekenhuis.nl

\section{References}

[1] Velasco-Tirado V, Alonso-Sardón M, LopezBernus A et al. Medical treatment of cystic echinococcosis: systematic review and meta-analysis. BMC Infect Dis 2018; 18: 306

[2] Kern P, Menezes da Silva A, Akhan O et al. The echinococcoses: diagnosis, clinical management and burden of disease. Adv Parasitol 2017; 96: 259-369

[3] Ramia JM, Figueras ], De La Plaza R et al. Cysto-biliary communication in liver hydatidosis. Langenbeck's Arch Surg 2012; 397: 881-887

[4] Dolay K, Akbulut S. Role of endoscopic retrograde cholangiopancreatography in the management of hepatic hydatid disease. World I Gastroenterol 2014; 20: 1525315261

[5] Al-Toma AA, Vermeijden RJ, Van De Wiel A. Acute pancreatitis complicating intrabiliary rupture of liver hydatid cyst. Eur J Intern Med 2004; 15: 65-67

\section{Bibliography}

Endoscopy 2022; 54: E98-E99

DOI 10.1055/a-1388-5323

ISSN 0013-726X

published online 30.3 .2021

(c) 2021. Thieme. All rights reserved.

Georg Thieme Verlag KG, Rüdigerstraße 14,

70469 Stuttgart, Germany

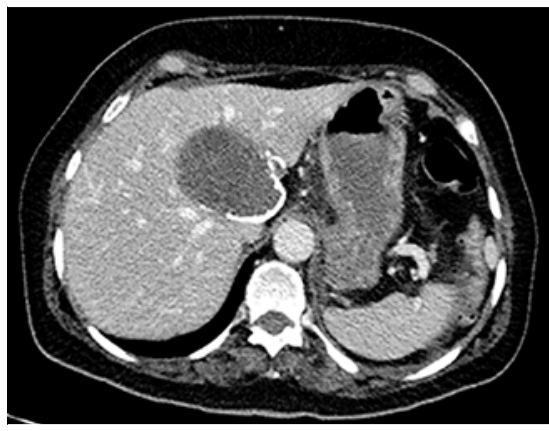

- Fig. 4 Abdominal computed tomography scan shows a multilocular hydatid cyst of 66 by 48 millimeters.

\section{ENDOSCOPY E-VIDEOS}

https:/|eref.thieme.de/e-videos

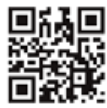

Endoscopy E-Videos is an open access online section, reporting on interesting cases and new techniques in gastroenterological endoscopy. All papers include a high quality video and all contributions are freely accessible online. Processing charges apply (currently EUR 375), discounts and wavers acc. to HINARI are available.

This section has its own submission website at https://mc.manuscriptcentral.com/e-videos 